\title{
Validating the measurement system using MSA: terminal angle inspection process for mounting in hoses with application in agricultural machines
}

\section{Validando o sistema de medição utilizando MSA: processo de inspeção do ângulo de terminais para montagem em mangueiras com aplicação em máquinas agrícolas}

Tábata Caroline de Assis ${ }^{1, *}$, André Luis Alves Rodrigues ${ }^{1}$, Lise Virgínia Vieira de Azevedo ${ }^{1}$, Rita de Cássia Mendonça Sales ${ }^{1}$

\begin{abstract}
The objective of this work is the application of the MSA (Measure Analysis System) to evaluate the system of measurement of the angle of metallic terminals in agricultural hoses, analyzing the parameters of operator repetitiveness, instrument reproducibility and tolerance to detect quantitative anomalies within the manufacturing process of these parts. The methods of measurement applied, angle transducer and profile projector were compared and it was observed that the profile projector was the best method applied for the process validation, since its total variation takes into account the parameters defined according to the recommendations of the American automakers AIAG, which states that the total change must be less than $30 \%$ to be considered acceptable.
\end{abstract}

Keywords: Mounting angle; MSA; Couplings inspection.

\section{RESUMO}

O objetivo deste trabalho é a aplicação do MSA (Measure Analysis System/Análise do Sistema de Medição) para avaliar o sistema de medição do ângulo de terminais metálicos em mangueiras agrícolas, analisando os parâmetros de repetitividade do operador, reprodutibilidade do instrumento e tolerância para detectar existência de anomalias quantitativas dentro do processo de fabricação destas peças. Os métodos de medição aplicados, transferidor de ângulo e projetor de perfil, foram comparados e observou-se que o projetor de perfil foi o melhor método aplicado para a validação do processo, pois a sua variação total atente os parâmetros definidos de acordo com as recomendações das montadoras americanas AIAG, que estabelece que a variação total deve ser menor que 30\% para ser considerado aceitável.

Palavras-chave: Ângulo de montagem; MSA; Inspeção de terminais.

${ }^{1}$ Faculdade de Tecnologia de São José dos Campos - Prof. Jessen Vidal - São José dos Campos (SP) - Brazil 


\section{INTRODUCTION}

The industries that supply to the agricultural market and/ or automotive, which own the ISO $9000^{(1)}$ and ISO/TS $16949^{(2)}$ certification needs to demonstrate the product validation capacity through the measurement system to assure the product quality and attend the normative requirement properly. Almeida e Sehnem ${ }^{(3)}$ quote that, "The reliable measurement process in the factory floor, with little variation, owns the fundamental and determinant role in the quality assurance and competitiveness such as that to satisfy the international practices and consequently, to participate of the global network of suppliers".

Generally, this competitiveness is measured in such a way that the supplier who owns the bigger process control becomes the favorite in the products and projects quotation moment, highlighting between the others.

Agricultural companies demand a level of quality almost so strict that the automakers, when it comes to standardization and validation of the production process. For that, the industries follow the crescent search for the stability and reliability of product quality, the using of measurement methods for the production part approval process validation (PPAP), becomes mandatory to prove the product compliance with the required tolerances.

According to Shrotri \& Dandekar ${ }^{(4)}$ PPAP is an important part of product development process allowing producers to evaluate the components and subsystem which they receive from supplier and establishing confidence in the suppliers management system. Although individual manufacturer have their own particular requirements, the Automotive Industry Action Group (AIAG) has developed a common PPAP standard as "Advanced Product quality Planning Process" (APQP) and encouraging the use of common terminology and standard forms to document project status.

Therefore, the resulting data of the measurements are used with high frequency in the productive process to determine if it is or not inside de control limits calculated considering the tolerance required by the client. Besides that, Mast $\&$ Wieringen ${ }^{(5)}$ define that these are the two sources that affect the data collection method. MSA (Measurement Systems Analysis) is used to measure the precision and accuracy of data or to measure the quality of data due to operators and method.

The MSA Reference from the $\mathrm{AIAG}^{(6)}$ defines that "measurement system is the collection of instruments or gages, standards, operations, methods, fixtures, software, personnel, environment and assumptions used to quantify a unit of measure or fix assessment to the feature characteristic being measured"; the complete process used to obtain measurements. A measurement system is a critical component for any quality improvement process. Product Quality is measured through statistical quality control (SQC) and every technique in SQC needs data. Therefore, if we have precise and accurate data, the results will be reliable and due to this, the product quality is monitored properly. Product Quality is generally affected by material, method, men and machinery, the MSA is concerned with men method/technique ${ }^{(7)}$.

Measurement Systems Analysis (MSA) is based on the philosophy that measurement error masks true process capability; therefore, it is performed prior to any process improvement activities in order to quantify and minimize the measurement error ${ }^{(8)}$. However, is possible appears a gap between the knowledge and practice of measurement studies and the actual deployment of measurement improvement techniques in organizations with formal quality management programs $^{(9)}$.

One of the production steps validation is to verify the measurement system, through the realization of periodic analyze studies, where the objectives are to verify if the process owns the statistical properties compatibles to the specifications and to take knowledge about the variation origins.

Without an analysis of the measurement system, there are no data to prove the efficiency and effectiveness of the measurement process control, making it impossible to validate the parameters quantification that contemplate the confection of the product.

\section{The factory process of assemblies with application in agricultural machinery}

The assemblies are used in a lot of agricultural machinery, from transmission kit's, air conditioning, to hydraulic systems in general. We call assembly all hoses that has at least in one of the extremities a metallic component, which could be a carbon steel tube with a superficial treatment or some coupling consisted in components made specially to adapt to the flexible hoses, with the objective of connecting it by the way of screws with the agricultural machinery.

The fabrication process of an assembly consists in the union of a hose already finished with a metallic item. The first step is the selection. For that it can occurs without any mistakes, it's necessary to inspect the parts in the receivement, to assure that non-compliant parts do not continue to the next step. For this to occur without errors, a consistent process is indispensable where the inspector has to be endowed with too much experience for visual detection and mastery of the measurement instruments needed for this work.

The couplings are inspected with the Skip-lot methodology, which is a smart way to do an inspection of items relating them with the supplier qualification, that is, provides a smaller sample size for the inspection purpose as compared to the single sampling plan. Skip-lot sampling plans have been widely used in industries to reduce the inspection cost ${ }^{(10)}$.

As pointed out by Hsu, the skip-lot sampling schemes are economically advantageous and useful to minimize the cost of the inspection of the final lots ${ }^{(11)}$.

When there is quality in the inspection measurement system, there is an increase in the reliability of the collected data, ensuring that it is not being generated erroneously and, in addition, there 
are reduced costs involved, such as less time to stop production and non-compliant components. These factors must be surpassed by the final quality guarantee of the finished product. Because of it, according to Da Fonseca ${ }^{(12)}$, "The quality engineers have the responsibility of to identify the statistical properties most important to the use of the data. It's their responsible, also, to assure that these properties are the base to choose the measurement system".

Therefore, the objective of this article is to determine, using the measurement system analyses studies, the best method to measure the coupling angles applied in agricultural machines, and to assure, after inspection, the process flows without the existence of quantitative anomalies in these systems.

\section{MATERIALS AND METHODS}

\section{Measurement instruments details}

The studies were performed with two instruments, where the objective was to validate the process with at least one of them. The first analysis will be made with a protractor angle (HOL NO-5001) that the measurement unit is degree. The instrument's resolution is $1^{\circ}$ and it owns a RBC calibration certificate, signed on September $10^{\text {th }} 2015$, with the periodicity of 24 months.

The second analysis will be used a profile projector (Mitutoyo), whose the measurement unit is degree. The instrument's resolution is $0.01^{\circ}$ and it owns a RBC calibration certificate, signed on September $25^{\text {th }} 2015$, with the periodicity of 24 months.

\section{Specimens' preparation}

The specimens were selected and identified following the same standard as the first specimen, with a numbered label to identify them.

All the measurements were performed with the same specimens, according to the amount necessary to the study effectiveness, being that, in the stability study it were used 05 specimens, in the tendency study it was used only one specimen (standard block) and in the repeatability and reproducibility study it was used 10 specimens.

The nominal angle value of these specimens is $90.5^{\circ}$, being that the tolerance is $\pm 2^{\circ}$, considering the specified value by the blueprint's client.

The product tolerance defines the instrument precision, taking in consideration that the MSA Reference from the $\mathrm{AIAG}^{(6)}$ establishes that "the measure increments should be small relative to the process variation or specification limits for the measurement purpose. The commonly known Rule of Tens, or 10-to-1 Rule, states that instrument discrimination should divide the tolerance (or process variation) into ten parts or more. This "rule of thumb" was intended as a practical minimum starting point for gage selection".

\section{Measurement system stability and tendency system calculation}

The instrument measurement stability was verified through 05 specimens of the same model of metallic coupling, obeying a period of 20 measurement days, whose calculations was adapted according MSA Reference from the AIAG and Ribeiro and Ten Caten $^{(6,13)}$

The instrument tendency was verified through 15 measurements of the same specimen block and by the same operator in the same day.

All charts and quantity data is result of software MINITAB $15^{(14)}$, following the instructions of the MSA Reference from the $\mathrm{AIAG}^{(6)}$ to calculate all values.

\section{RESULTS AND DISCUSSION}

\section{Stratification of the measurement system efficiency}

To select the measurement system who was needed an improvement, it was performed a repeatability and reproducibility study in each characteristics needed for validation and it was elaborated a Pareto chart considering the total variation presented in each one of the characteristics, such as the Fig. 1. Through this stratification, it was selected the mounting angle characteristic for study, because, through this, it's possible to analyze the cause of measurement deficient that is generating the reprobation of the study, whose variation is bigger than the permissible ${ }^{(6)}$.

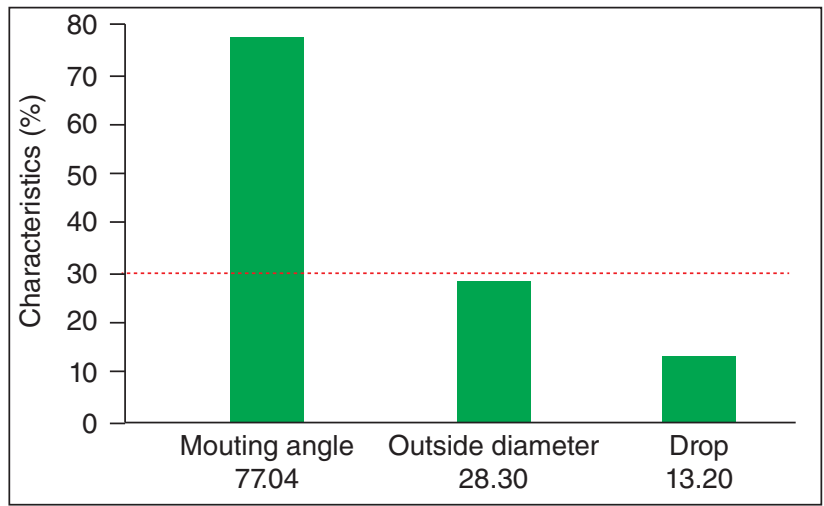

Figure 1: Stratification of the biggest variation.

\section{Stability evaluation measurement system}

The study analyzed the stability of the measurement instrument actually used in the process and another instrument, an alternative, with better precision. The collected results using the protractor angle, the actual instrument, were used to performing the calculations to define the control limits and, it was possible to generate the control charts. The mean chart was plotted on Fig. 2A and the range chart is represented on Fig. 2B.

Analyzing the Figs. 2A and 2B it is not explicit with any clue that the process can be unstable, as all of data were inside the control 
limits established, in mean chart between 88.687 and 91.832 and, in the range chart between 0.0 and 5.762 . Besides that, there is a good alternation between the superior point and inferior half into the plot and it does not present more than 07 consecutive points, what could indicate some biased influence.

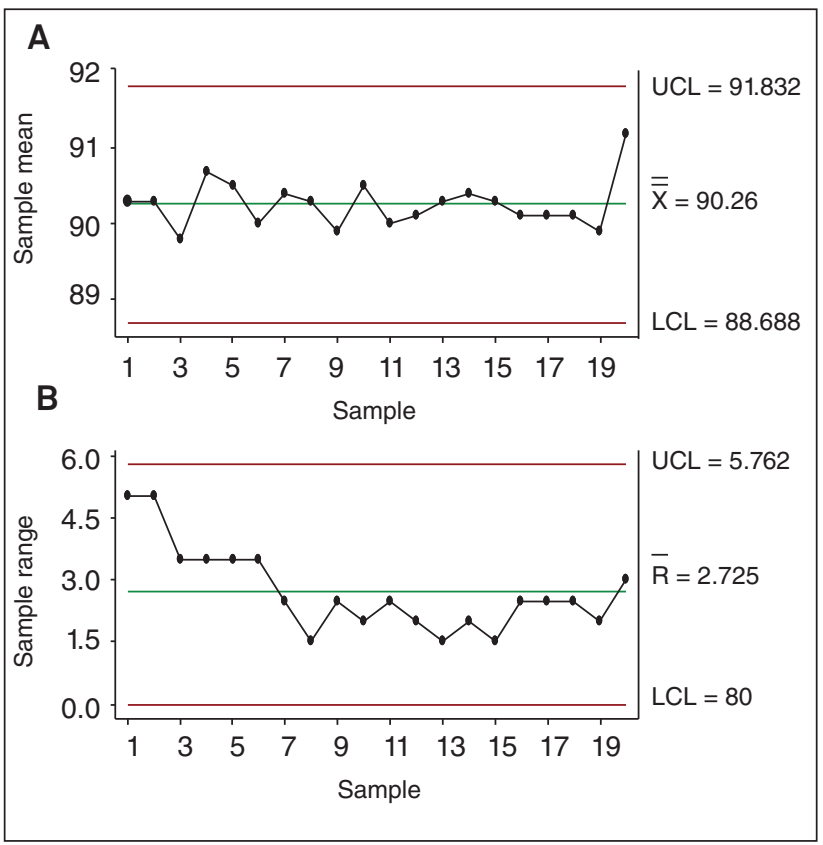

Figure 2: Measurements with the protractor angle: A) Mean chart and B) Range chart

The data were also collect to evaluate the stability with the profile projector. Figures $3 \mathrm{~A}$ and $3 \mathrm{~B}$ represent the mean and average chart, respectively, obtained through the measurements executed with the profile projector.

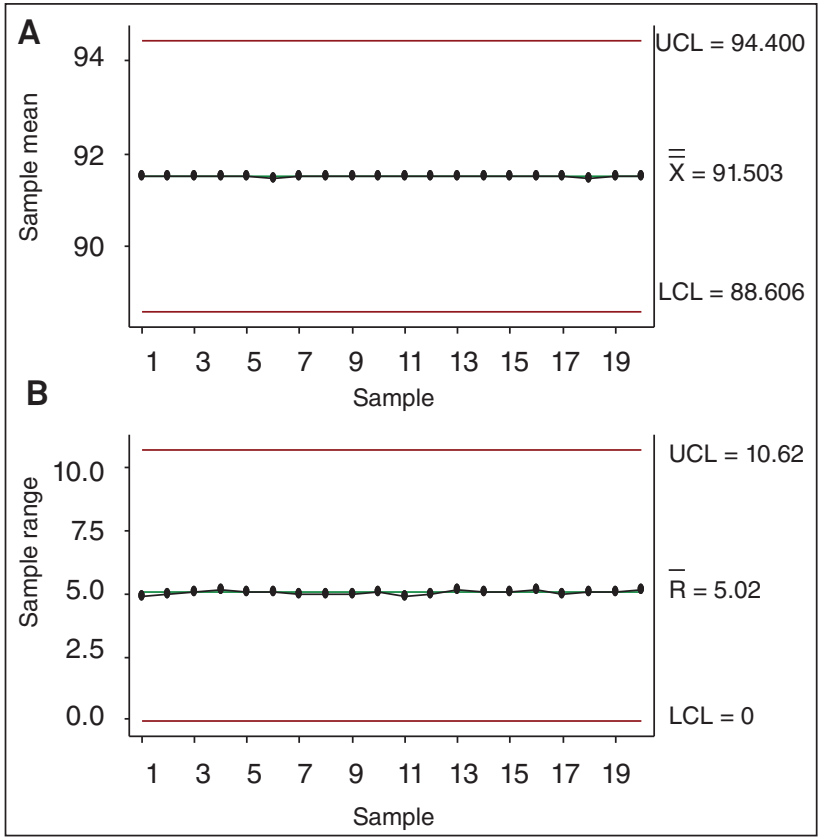

Figure 3: Measurements with the profile projector: A) Mean charts and B)Range charts
Analyzing the charts resultants of the measurements with the profile projector (Figs. 3A and $3 \mathrm{~B}$ ) there is no clue that the process could be unstable, considering all of the data which are inside the control limits established, in the mean chart between 88.606 and 94.400, and, in the range chart, between 0.0 and 10.62 .

It were observed that the points were plotted in both charts really close to the mean, indicating that the daily mean was keeping almost the same until the end of the study. Besides that, because of more instrument accuracy, the specimens' range get bigger, making that the limit control presented more opening in both charts. The result showed in the Figure 3B, also, does not present more than 07 consecutive points, what could indicate some biased influence.

\section{Tendency evaluation measurement system}

The tendency study was applied to evaluate of measurement instrument used actually in the process, the protractor angle.

With the collected results for the study, it was possible to generate the histogram, showed in the Fig. 4A, where appoints that, between the performed measurements with the same standard, the value of $90^{\circ}$ was found 9 times, being the biggest predomination measurement during the study. For Albertazzi e Souza ${ }^{(15)}$, the tendency analyze is the method that correspond to the difference between the indications mean obtained and a reference value, that can be originating from a standard or an example of the product sold that passed previously in a measurement process whose results an uncertain and at least ten times smaller.

Figure $4 \mathrm{~B}$ shows the individual values of the measurements with the protractor angle, where it is possible to analyze the error positioning of the measurements inside the control limits

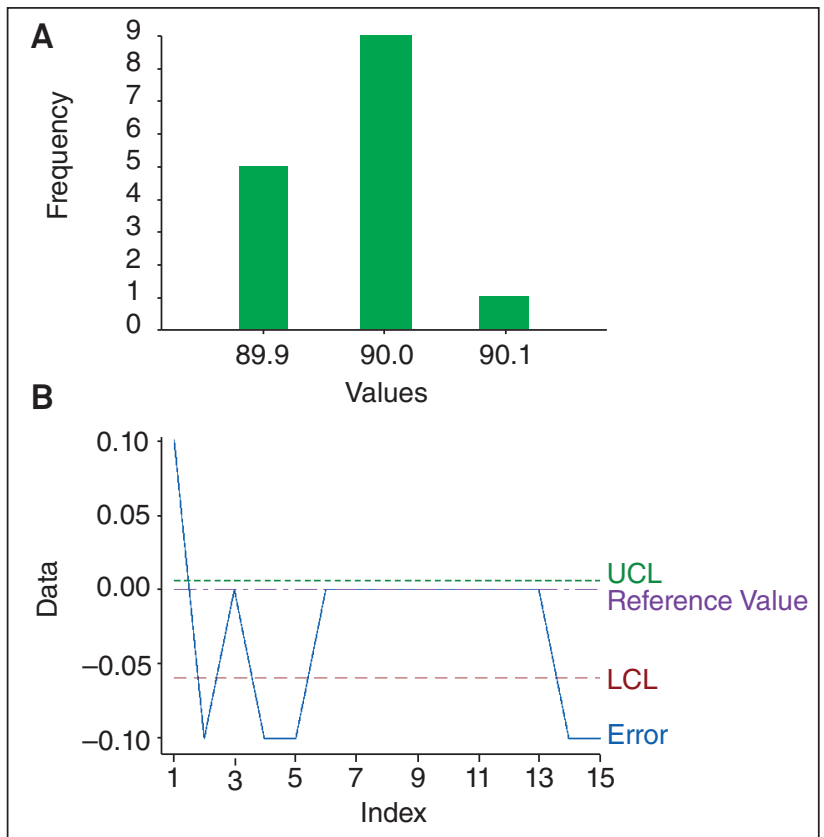

Figure 4: Protractor angle measurements: A) Tendency histogram and B) Individual values chart of the tendencies 
to identify the largest error range in the measurements with the standard, which in this case it was $0.1^{\circ}$.

With the collected data of the profile projector studied, it was generated an histogram (Fig. 5A), where it is possible to notice that the nominal value was found 13 times, indicating that this is the predominant during the measurements. In addition, it was possible to plot the individual error values where the largest range was $-0.4^{\circ}$.

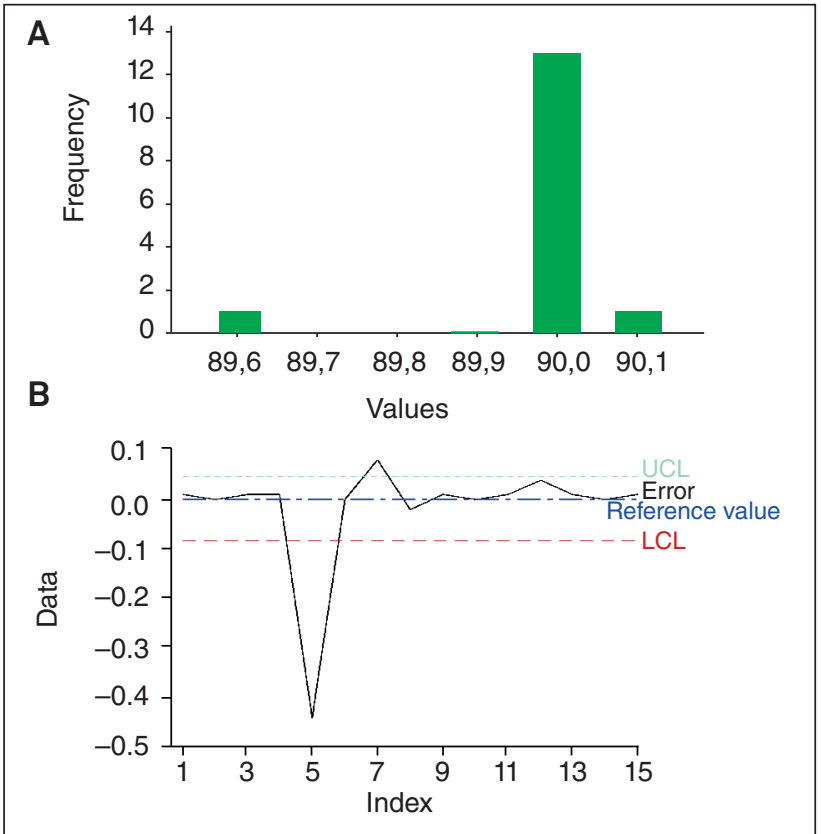

Figure 5: Profile projector measurements: A) Tendency histogram and $B$ ) Tendencies Individual values chart.

Performing an analysis more deeply, neither of those instruments presented some significant tendency in the statistic point of view, because, in both cases, the statistic $t$ is smaller than $t$ student (protractor angle statistic $\mathrm{t}=1.7398$ and $\mathrm{t}$ student $=2.1450$ and in the profile projector statistic $t=0.5864$ and $t$ student $=2.1450$ ). By the analysis of the Fig 5, we can notice that in both cases, the error bypasses the established limits, but it is sporadic the bypasses, what indicates no type of tendency, but, random errors.

\section{Variation evaluation measurement system}

According to Ribeiro and Ten Cate ${ }^{(13)}$ variability is always present in any production process, regardless of how well it is designed and operated. If we compare any two units produced by the same process, they will never be identical. However, the difference between parts may be large, leading to the appearance of defective products, or may be barely noticeable. In addition, the sources of variability may act differently on the process. According to the source of variability, the result can be: a) small piece-by-piece differences (operator ability, differences in raw material), b) gradual change in process (tool wear, daytime temperature) and c) abrupt change in the process (change of procedure, drop in current, change of set up).
Using the protractor angle, the data were collected to analyze of the system variation and calculate the variation considered in studied the repeatability and reproducibility, such as the relation with the measurement unit, specimen variation and tolerance. Analyzing the results, in the first place, it was observed that the category numbers were really small, in this case, it was found the category numbers $=2$. The category numbers between 1 and 2 means that the quantitative values collected would be more efficient if they were used the attributive method, that is, if it is or not in accordance to the tolerance, 0 or 1 . Through this information, it is possible to notice that the actual instrument is not capable to control the process through quantitative measurements.

The most useful data to make the study are the analyses relating to the tolerance, because, after these analyses, it is already possible detect if the measurement system is attending the established parameters. Besides that, when observed the VE result (77\%) much bigger than VA $(2.2 \%)$, we can already conclude that it is necessary to improve the measurement instrument, because when the quotient of VE/VA is bigger than 1.0; it means that the measurement instrument is not adequate.

The operators reproducibility resulted in a value considered extremely low, indicating that there is no discrepant difference between the operators.

The most important parameter, compared with the others, to validate the study is the total variation relating to tolerance. The established criteria by the MSA Reference from the AIAG are these: a system with R\&R equal or smaller than $10 \%$, means that the system is capable, $\mathrm{R} \& \mathrm{R}$ between $10 \%$ and $30 \%$ indicates that is conditionally capable and, a system with $R \& R$ bigger than $30 \%$ demonstrates the incapacity in the measurement system ${ }^{(6)}$.

The total variation relating to tolerance indicated the incapacity of measurement system, because, its value is equal to $77.04 \%$, that means incapable. The total variation above $30 \%$ is a sufficient reason to reprove the system. The charts analyzed can identify the deficient parameters in the measurement system; such a way they can be compared to an alternative to analysis of the efficacy of each one of these systems and with the objective to select the most capable measurement method to validate the process. The ranges and means control charts, plotted through the protractor angle measurements are showed in the Figs. $6 \mathrm{~A}$ and $6 \mathrm{~B}$, respectively.

Analyzing the Figs. 6A and 6B, is possible to find clues showing that the process is unstable, considering that in the means analyses with the repeatability and reproducibility. The points should be plotted such a way that could demonstrate a good alternation outside the control limits, established between 88.738 and 90.529 , because, if the alternation is missing, it means the instrument is not capable to detect variations, that is, the instrument is not measuring accurately.

About the range control charts (Fig. 6B), all the points should be plotted inside the control limits, between 0.0 and 2.252. The point plotted relative to the specimen 10 is outside the superior limit, what happened just with the first operator, what shows 
that it is really probable that this operator committed an aleatory mistake in some of his repetitions, what, consequently, made the range in his measurements bigger than the allowed, that is, bigger than 2 degrees for this study.

In Fig. 7, it was possible to analyze graphically all of variation components. It can be noticed the discrepancy between the repeatability and the reproducibility, all of them relating to tolerance. The total variation is much bigger than $30 \%$, demonstrating the incapability in the measurement system.

Fig. 8A represents the average of each one specimen and all values found during the measurements, being that, each operator is responsible for half of this, so, it is already possible analyze the range, considered big, between each on of measurements with the mean. Besides that, it can be noticed by the chart that, the responsible to execute the measurement do it with the difference about a half of degree in each measurement, because, the instrument's resolution do not allow measurements with closer

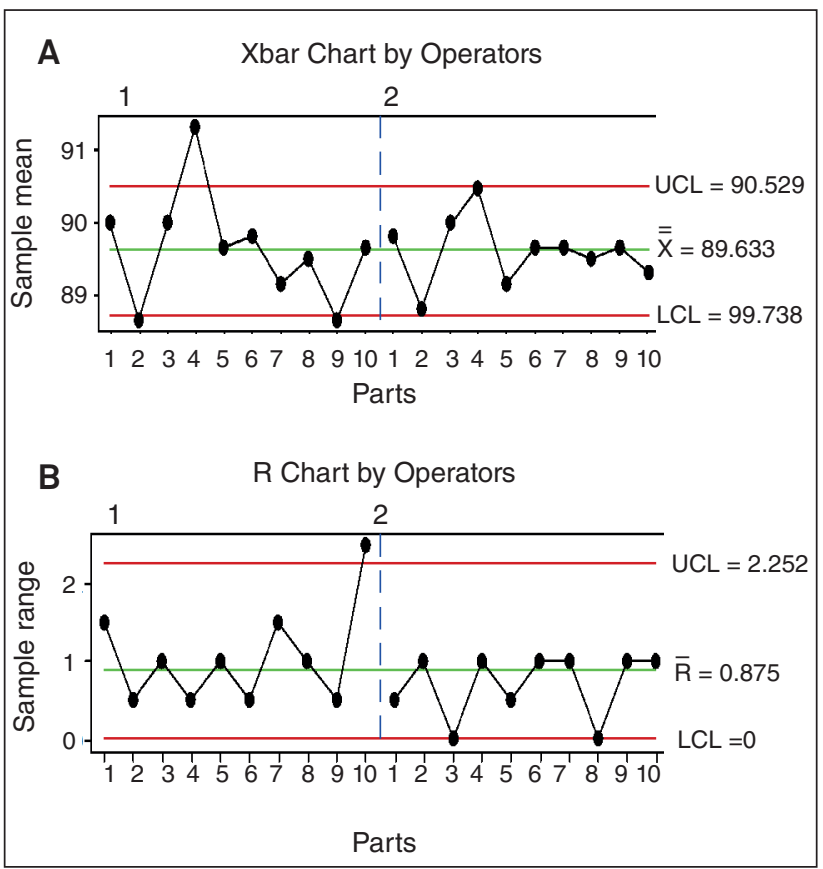

Figure 6: Protractor angle: A) Mean chart and B) Range chart

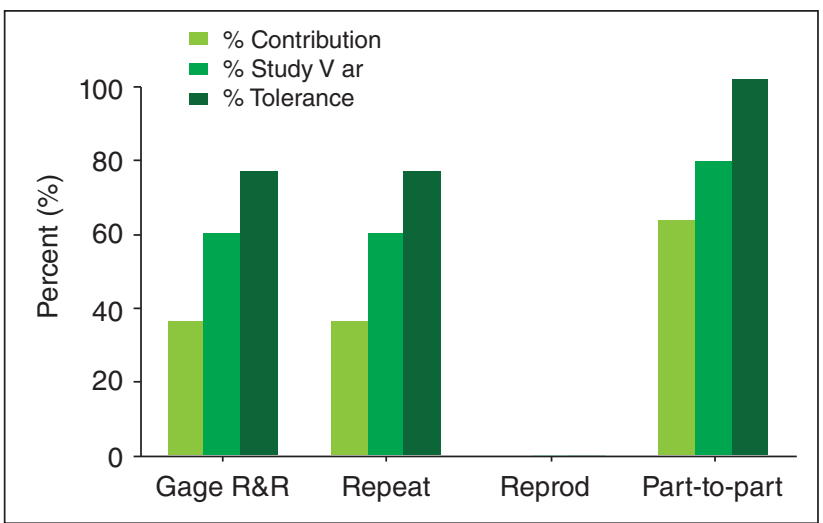

Figure 7: Variation components of the measurements performed by protractor angle. plotted points, what could be possible only if it was used a scale with better resolution. In Fig. 8b, it is clear the agreement between the operators, because the measurements between them were not much different. Therefore, it was possible to conclude that there is no need of a recycling application in the measurement instrument training, because, neither of them is doing an incorrect way of measurement in relation to the other, that is, the mean of both was very similar.

Figure 9 represents the measurements mean by specimen, of each one of the operators. It is clear to say that, even than the final mean by operators are closer, there were some parts that possibly let the operators in doubt and made them confuse and, because of this, the range of some measurements become high due to the poor resolution of equipment. However, considering the equipment resolution, the range is not in fact so high; in view of the higher points differ from each other in the maximum $1.5^{\circ}$.

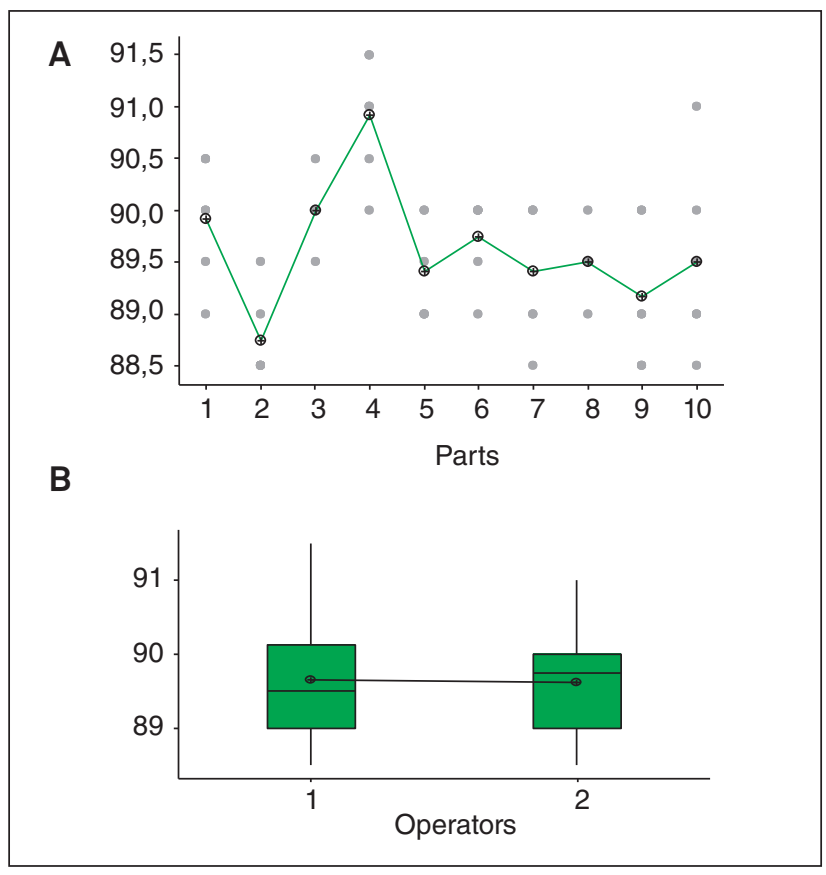

Figure 8: Protractor angle: A) Measurements by part and B) Measurements by operator

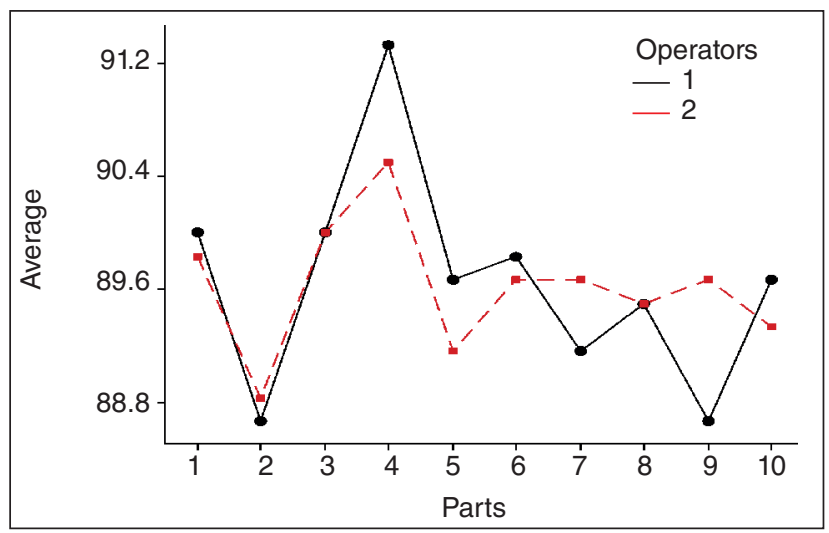

Figure 9: Specimen means by operator, performed with protractor angle. 
The operator that does not have an instrument with better scale, that is, with more resolution, cannot classify the part performing a measurement with more accuracy, in such a way he could make the range smaller.

The measurements using a profile projector were also carried out, which, besides the precision is better than the protractor angle attending the specified in MSA Reference from AIAG, that is, its resolution is bigger than $10 \%$ of the tolerance established according to specified to this coupling ${ }^{(6)}$.

The data collect method was same as the measurements with protractor angle, but not in the same day due to the time necessary to execute the measurements with profile projector. It was noticed that the time necessary to measure a part with profile projector was much bigger than the actual instrument, becoming unviable the inspection with a profile projector inside the production line. For that, it could be possible the study with this instrument, the data were collected and all necessary parameters were calculated considered in R\&R analyses. Through those results, one of the parameters that attract more attention is the category number $=35$, because it is really higher than the category number performed by the other instrument.

According to MSA Reference from $\mathrm{AIAG}^{(6)}$, a category number equal or larger than 5 , means that system is a favorable situation to perform a quantitative R\&R study. In other words, it means that the selected specimens are effective when considered its parameter variability and the profile projector was capable to detect this variation. The VE result (9.90) continues larger than VA (1.68), what indicates that it is still recommendable improve the measurement instrument, but the value is not so higher than the anterior, which the proportion was 35:1.

About total variation, the most important parameter to validate the study, this, presented a partial capacity, conditionally, but, much closer to the capacity considered great, because its value is $10.04 \%$, what differs $0.04 \%$ from the required to an excellent measurement system. In addition, it was performed a graphical analysis to plot the values presented by the measurement system, being that, firstly will be presented the mean and range control charts, in the Figs. $10 \mathrm{~A}$ and 10B, respectively.

Figures $10 \mathrm{~A}$ and $10 \mathrm{~B}$ present evidences that the process is stable, considering that in the mean chart of repeatability and reproducibility analyses, the points were plotted in such a way that show a good alternation outside of control limits, established between 91.106 and 91.336. This phenomenon happens because the control limits suffered a range reduction because of its relation with all measurement means and range average, considering the results were more accurate and consistent.

It is noticed an alternation between the specimen means that is caused by the high category numbers, what provided to the instrument demonstrate its capacity to detect variations in the measurement process.

In the range chart, all the points were plotted inside control limits, between 0.0 and 0.2896 , what were reduced compared to the protractor angle limits control, due to a smaller mean of range. All the points plotted inside control limits showed the process is completely stable. In addition, it was possible to analyze all components variation (Fig. 11), where it was noticed that the difference between the repeatability and reproducibility relating to the tolerance was reduced significantly. The total variation relating to tolerance is much smaller than $30 \%{ }^{(6)}$, what demonstrated a high capacity of the measurement system.

Figure 12A represents all the values found during the measurements, and each specimens means for that it can be analyzed the distance between both. It is clear to notice that the measurements were much closer and, it was possible only because of an instrument that provided to the operator a better accuracy in the measurements. In Fig. 12B, it is possible to see the agreement between the operators; the total measurement means by operator was really closer. Therefore, it was concluded that it

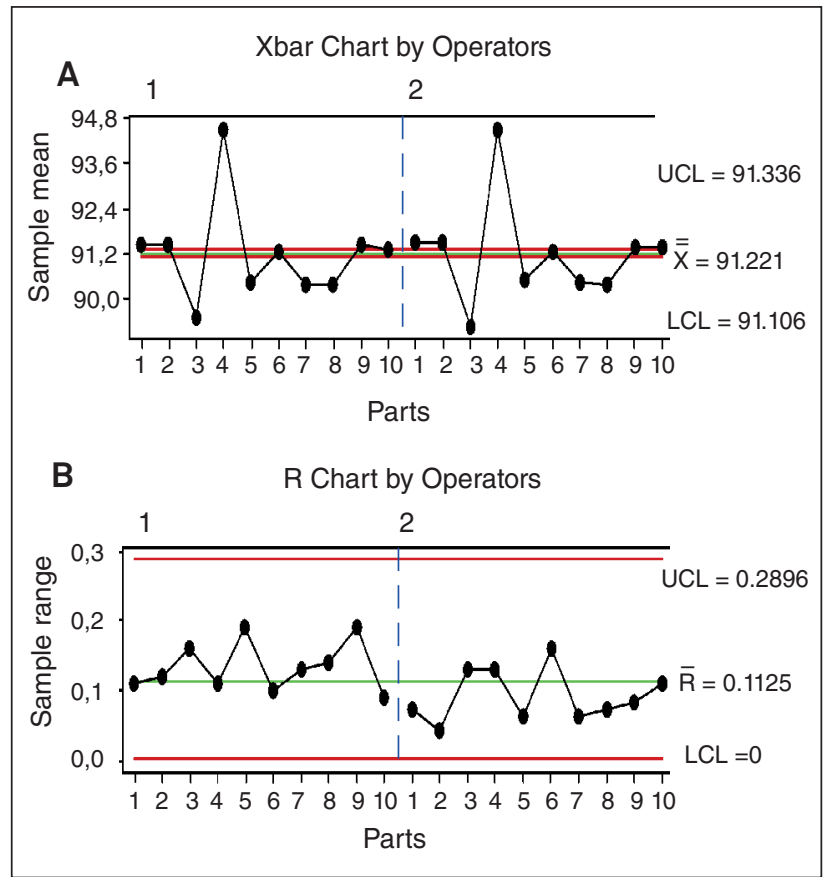

Figure 10: Measurements performed by profile projector: A) Mean chart and B) Range chart.

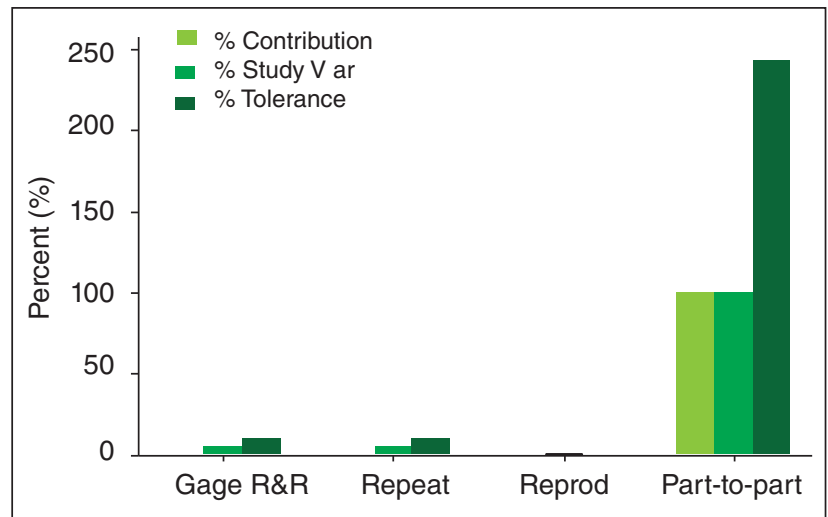

Figure 11: Variation components of the measures performed by profile projector. 
was not necessary a measure training recycle application, because, neither of them performed the measurements of an incorrect way relating to another, that is, both means are similar.

The chart in the Fig. 13 presents the specimens measurements means by operator, where it was possible to notice that operators specimens means were much closer and it is almost impossible to see the range between its. Both operators presented a high agreement because of the increasing in the instrument precision, what became the measurements clearer and more reliable.

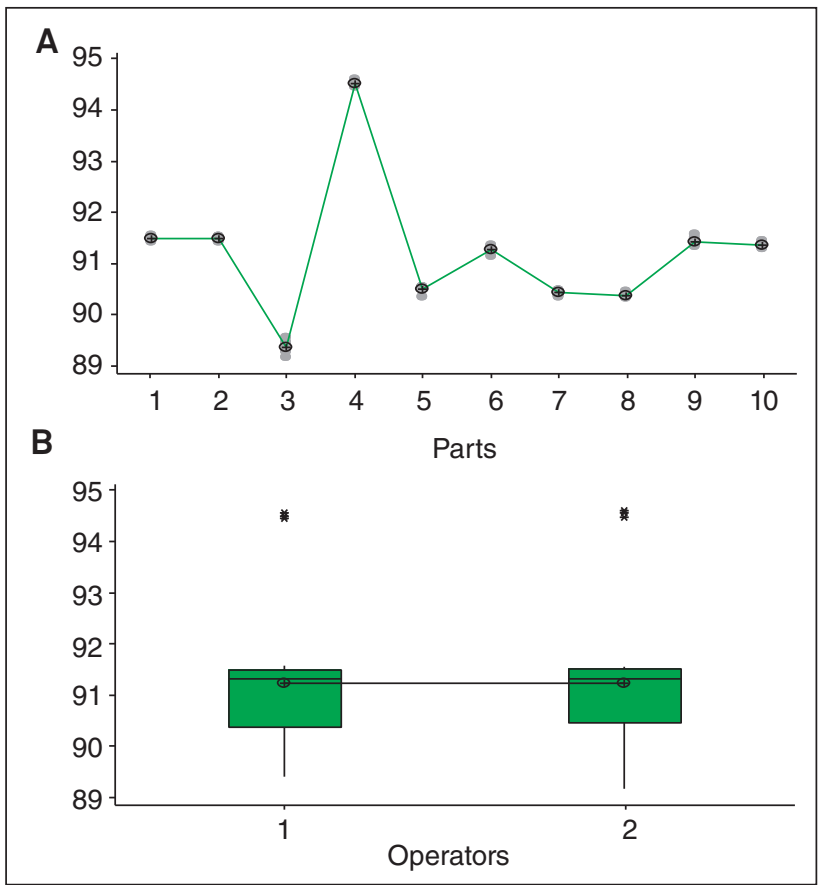

Figure 12: Profile projector: A) Measurements by part and B) Measurements by operator

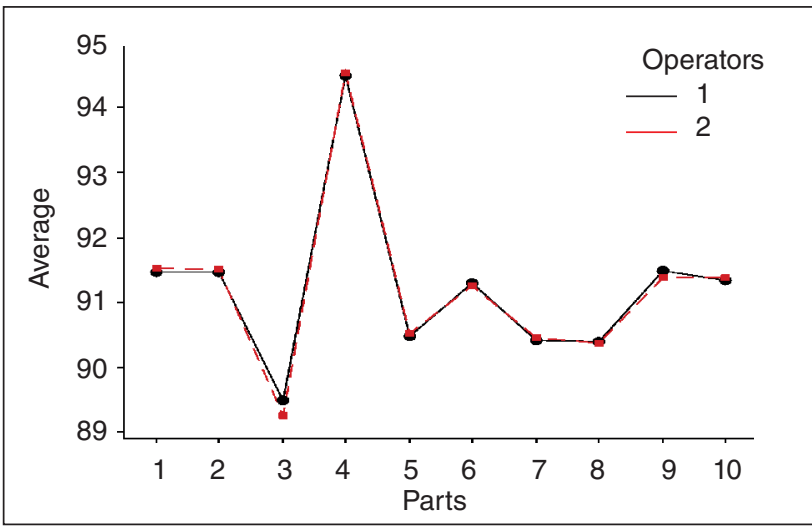

Figure 13: Specimen means by operator, performed by profile projector.

\section{CONCLUSION}

The MSA usage contributes a lot in measurement system analyses and system validation in such a logical way, not aleatory. Using this tool, it was noticed the actual process variation, which was not compliant and, provided the best method to execute the same function in such a way to present more reliability in the measurement system.

During the studies, it was verified that the protractor angle did not attend the clients' blueprint requirement, so, it was proposed that all measurements after finishing the studies were performed by profile projector. Although it demands more time than the other method to inspect the coupling's angle, it presents a higher assurance and, considering the parts are not $100 \%$ inspected (it is used the Skip-Lot methodology), the time would not be so impacting to the production process. Using MSA was possible to conclude that the best process validation method of coupling angle inspection is using a profile projector, so, the using of protractor angle should be avoided in the couplings receipt.

\section{ACKNOWLEDGMENTS}

The authors acknowledge the financial support received for this work from the National Research Council CNPq, Grant 460375 / 2014-8.

\section{REFERENCES}

1. ABNT, 2001. ASSOCIAÇÃO BRASILEIRA DE NORMAS TÉCNICAS.NBR ISO 9001/2000: Sistemas de Gestão da Qualidade. Rio de Janeiro, 2001.

2. ABNT, 2004. ASSOCIAÇÃO BRASILEIRA DE NORMAS TÉCNICAS. NBR ISO/TS 16949/2004: Sistemas de Gestão da Qualidade - Requisitos particulares para aplicação da ABNT NBR ISO 9001:2000 para organizações de produção automotiva e peças de reposição pertinentes. Rio de Janeiro, 2004.

3. ALMEIDA, D.; SEHNEM, F. Construção e validação para o processo produtivo. Dissertação (Pós-graduação em Engenharia da Qualidade com ênfase em Black Belts) - Faculdade de Engenharia de Minas Gerais - FEAMIG, Minas Gerais, [s. d.]. p. 2. Disponível em: <http://www.cimm.com.br/portal/publicacao/329construcao-e-validacao-de-um-sistema-de-medicao-para-oprocesso-produtivo > Acesso em: 15 agosto 2016.

4. Shrotri, A.P.; Dandekar A.R.. PPPA - An effective tool for vendor quality management. International Journal of Emerging Technology and Advanced Engineering, 2 (4):1-4, 2012.

5. MAST, J.D., WIERINGEN, W.V., Measurement System Analysis for Bounded Ordinal Data. Quality Reliability Engineering International 20:383-395, 2004.

6. IQA, 2010. INSTITUTO DE QUALIDADE AUTOMOTIVA. Análises de sistemas de medição - MSA, Manual de referência. $4^{a}$. Ed. São Paulo, 5-124,2010.

7. HOFFA, D.W., LUX, C. Gauge R \& R: An effective methodology for determining the adequacy of a new measurement system for micron-level metrology. Journal of Industrial Technology, 23(4):19, 2007.

8. Harry, M. J., Lawson, J. R. Six sigma producibility analysis and process characterization. New York: Addison-Wesley, 1992.

9. Smith, R. R., McCrary, S. W., Callahan, R. N. Gauge repeatability and reproducibility studies and measurement system analysis: A multimethod exploration of the state of practice. Journal of Quality Technology, 23(1): 1-11, 2007. 
10. BALAMURALI, SAMINATHAN; ASLAM, MUHAMMAD; JUN CHIHYUCK. A New System of Skip-Lot Sampling Plans including Resampling. Hindawi Publishing Corporation The Scientific World Journal Volume 2014, Article ID 192412, 6 pages.

11. HSU, J. I. S., "A cost model for skip-lot destructive testing," IEEE Transactions on Reliability, 26 (1): 70-72, 1977.

12. A FONSECA, MARIANA PAES. A Análise do Sistema de Medição (MSA) como ferramenta no controle de processos em uma indústria de dispositivos médicos descartáveis. Monografia - Universidade Federal de Juiz de Fora, Departamento de Engenharia de Produção. Minas Gerais, 2008. p. 2.
13. RIBEIRO J.L.D.; TEN CATEN C.S. Controle Estatístico de Processo - Cartas de Controle para Variáveis, Cartas de Controle para Atributos, Função de Perda Quadrática, Análise de Sistemas de Medição. Série Monográfica Qualidade. Programa de PósGraduação em Engenharia de Produção. Universidade Federal do Rio Grande do Sul. Escola de Engenharia. Porto Alegre, 2012.

14. MINITAB INC. Minitab (Version 15) [Computer software]. State College, PA: Minitab Inc., 2007.

15. AlbertaZZI, A. G. e SOUZA, A. R. Metrologia Científica e Industrial. Barueri: Manole, p.244, 2008. 